\title{
Effect of Lingual Frenotomy on Tongue and Lip Rest Position: A Nonrandomized Clinical Trial
}

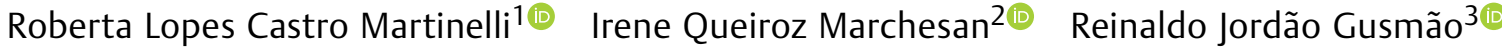 \\ Giédre Berretin-Felix ${ }^{4}$
}

${ }^{1}$ Lingual frenulum inspection Department, Hospital Santa

Therezinha, Brotas, SP, Brazil

2 Speech and Myofunctional Disorders Department, CEFAC Health and

Education, São Paulo, SP, Brazil

${ }^{3}$ Clínica Respirare Otorhinolaryngology Department, Universidade

Estadual de Campinas, Campinas, SP, Brazil

${ }^{4}$ Speech, Language and Hearing Sciences Department, Universidade

de São Paulo, Bauru, SP, Brazil
Address for correspondence Roberta Lopes de Castro Martinelli, PhD, Rua Cayowaá, 664, Perdizes, São Paulo, SP, 05018-000, Brazil (e-mail: robertalcm@gmail.com).

\begin{abstract}
Keywords

- lingual frenum

- ankyloglossia

- surgical procedure

- tongue
\end{abstract}

Introduction The tongue plays an important role in the development of craniofacial structures. At rest, the light and constant pressure of the tongue against the hard palate, counterbalanced by the pressure provided by proper lip sealing, serves as a guide for maxillary growth. Ankyloglossia makes tongue coupling against the hard palate difficult, impacting maxillary development, which may lead to breathing disorders.

Objective To verify the effect of lingual frenotomy on the resting position of the tongue and lips in infants with ankyloglossia.

Methods The sample consisted of 334 infants aged between 1 and 60 days old diagnosed with ankyloglossia. The groups were divided in: a) experimental group (EG), which consisted of infants whose mothers agreed with lingual frenotomy; b) control group (CG), which consisted of infants whose mothers either refused lingual frenotomy or were waiting for surgery. Both the position of the lips and of the tongue at rest were assessed while the infants were sleeping during the quiet sleep phase. For mothers who refused their infants to undergo the surgical procedure, a follow-up of the infants was proposed to verify possible interference of the frenulum with the resting position of the tongue and lips. Infants whose mothers agreed with surgery were referred for lingual frenotomy.

Results Regarding the position of the tongue and lips at rest at the initial and final assessments, the statistical analysis demonstrated significant differences between both groups.

Conclusion Lingual frenotomy enabled infants diagnosed with ankyloglossia to maintain both tongue coupling against the hard palate and closed lips at rest. received

September 29, 2020

accepted

December 20, 2020

published online

July 5, 2021
DOI https://doi.org/

10.1055/s-0041-1726050. ISSN 1809-9777. (c) 2021. Fundação Otorrinolaringologia. All rights reserved.

This is an open access article published by Thieme under the terms of the Creative Commons Attribution-NonDerivative-NonCommercial-License, permitting copying and reproduction so long as the original work is given appropriate credit. Contents may not be used for commercial purposes, or adapted, remixed, transformed or built upon. (https://creativecommons.org/ licenses/by-nc-nd/4.0/)

Thieme Revinter Publicações Ltda., Rua do Matoso 170, Rio de Janeiro, RJ, CEP 20270-135, Brazil 


\section{Introduction}

The tongue plays an important role in the development of craniofacial structures. At rest, the light and constant pressure of the tongue against the hard palate, counterbalanced by the pressure provided by proper lip sealing, serves as a guide for maxillary growth and expansion. ${ }^{1,2}$ The importance of tongue contact against the palate is demonstrated in studies that describe anatomical characteristics in cases of aglossia, with palate atresia being one of the reported consequences. ${ }^{3-5}$

Most qualified clinicians are aware of the negative impact of sucking and mouth breathing habits on the resting position of the tongue and lips; however, several clinicians overlook a third cause, which is the presence of ankyloglossia. ${ }^{1}$

Studies report that ankyloglossia makes tongue coupling against the hard palate difficult, impacting maxillary development, ${ }^{6-10}$ which may lead to breathing disorders during sleep. ${ }^{11-13}$ These alterations occur early in life, as orofacial growth is particularly fast in the first 2 years of life. ${ }^{11}$ This difficulty in palate coupling was confirmed in a study with infants diagnosed with ankyloglossia, in whom the tongue at rest tended to remain down-positioned in the oral cavity due to the mechanical restriction for its elevation. ${ }^{14}$

In addition to the negative effect of functional imbalances caused by ankyloglossia during the growth and development of the stomatognathic system, correction of the resting position of the tongue improves the positioning of the hyoid bone, reducing muscle strength on the mandible, thus avoiding occlusal alterations. ${ }^{10}$

Several studies have been published relating ankyloglossia to breastfeeding difficulties, ${ }^{15-19}$ sucking, ${ }^{20}$ chewing ${ }^{21}$ and speech, ${ }^{22,23}$ as well as sleep-related breathing disorders ${ }^{11-13}$ and craniofacial growth. ${ }^{6-10}$

However, few studies have related ankyloglossia with tongue position at rest. ${ }^{1,14}$ Resting the tongue against the hard palate acts as a natural orthodontic expander, serving as a guide for maxillary growth. ${ }^{1}$ In the presence of ankyloglossia, the lingual frenulum hinders the coupling of the tongue at rest against the hard palate, ${ }^{14}$ resulting in a high and narrow palate. ${ }^{1,11}$ Thus, an incorrect tongue positioning must not be neglected, as it interferes with orofacial growth, which is fast in the first years of life, as widely stated in the literature. ${ }^{11,24-26}$

The treatment of ankyloglossia is surgical, since the histological constitution of the lingual frenulum does not allow it to rupture alone or to be stretched by means of exercises. ${ }^{27}$

The indicated procedure for infants is lingual frenotomy, and its benefits for breastfeeding have been reported in several studies. ${ }^{15-20}$ However, exclusive breastfeeding is recommended only until the $6^{\text {th }}$ month of life, and may extend up to 2 years, while chewing, swallowing, breathing and speech are functions performed throughout life, and highly influenced by craniofacial growth.

Thus, the aim of the present study was to verify the effect of lingual frenotomy on the resting position of the tongue and lips in infants with ankyloglossia. We hypothesized that infants with ankyloglossia change the position of the tongue and lips after the tongue-tie release.

\section{Methods}

The sample consisted of 334 infants aged between 1 and 60 days diagnosed with ankyloglossia from August 2015 to March 2019. The research was approved by the Research Ethics Committee of the CEFAC Health and Education under the number 1.165.682. The mothers of the infants were previously informed about all the procedures and signed the Informed Consent Form.

The inclusion criteria considered for the present study were: healthy full-term newborns having Apgar scores $\geq 8$, diagnosed with ankyloglossia by means of the Neonatal Tongue Screening Test, popularly known as the tongue test. ${ }^{28}$ Prematurity, perinatal complications, craniofacial anomalies, neurological disorders and genetic syndromes, pacifier use, exclusive bottle feeding, nasal obstruction, as well as the impossibility of clinical evaluation of the tongue and lips at rest were the exclusion criteria.

For ethical reasons, the groups were not divided randomly: the experimental group (EG) consisted of infants whose mothers agreed with lingual frenotomy. The control group (CG) consisted of infants whose mothers either refused lingual frenotomy or were waiting for surgery. Both groups of mothers (of the EG and CG) agreed to participate in the research.

Both the position of the lips and of the tongue at rest were assessed while the infants were sleeping on their mother's lap during the quiet sleep phase ${ }^{29}$-when the babies had their eyes closed, without movements, and regular breathing. The position of the lips was assessed by means of visual inspection, observing whether the lips were closed, half-open or open at rest ( - Fig. $\mathbf{1}$ ).

To verify the tongue position at rest, the maneuver described by Martinelli et al. ${ }^{14}$ was performed. Facing each infant, the evaluator opened the mouth of the infant and raised the lateral margins of the tongue using the right and left gloved index fingers while the gloved thumb was positioned on the chin

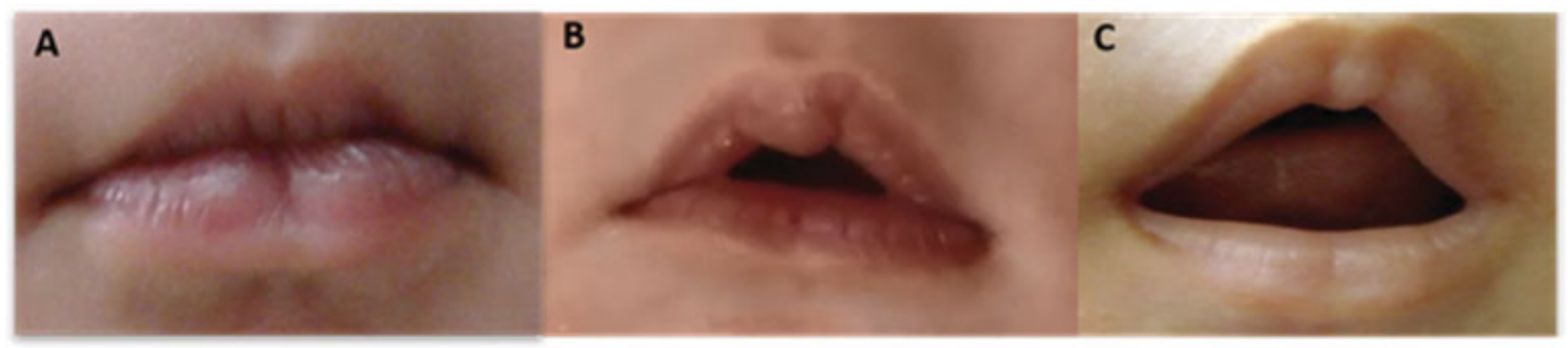

Fig. 1 Lip posture at rest. In A, closed, in B, half-open, and in C, open. 


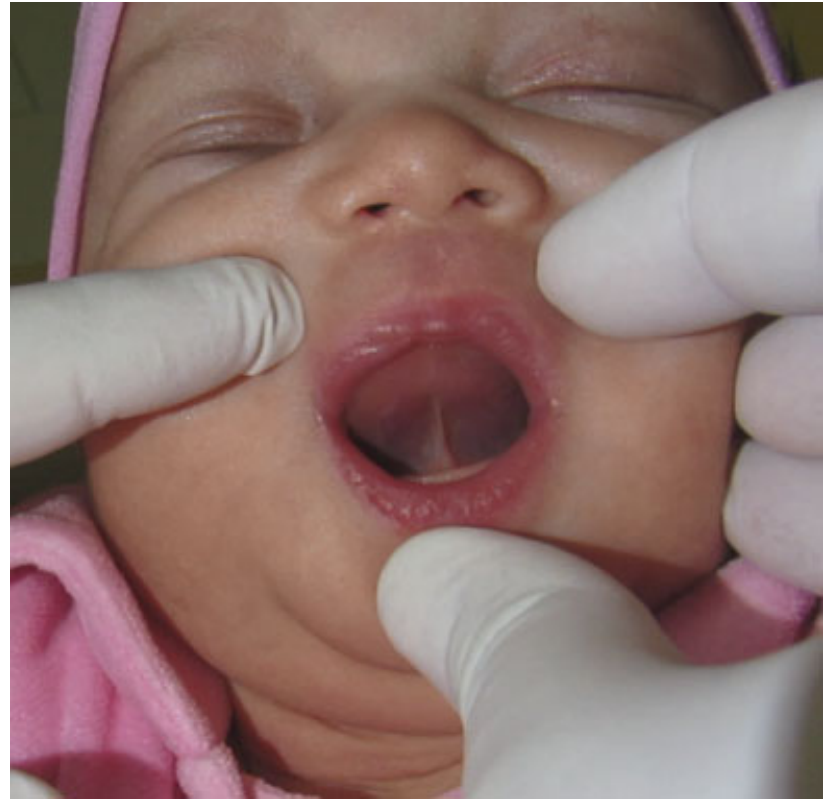

Fig. 2 Maneuver to visualize tongue position at rest.

region. The maneuver allowed the visualization of the position of the tongue at rest ( $\mathbf{- F i g . 2}$ ). It was observed that the tongue was either elevated, that is, the anterior third of the tongue in contact with the palatine rugae, or elevated with the inferior surface being pulled down by the lingual frenulum or downpositioned in the oral cavity (-Fig. 3 ).

After the diagnosis of ankyloglossia (score $\geq 7$ according to the screening) in the first 48 hours of life (initial assessment), for mothers who refused their infants to undergo the surgical procedure, it a follow-up of the infants was proposed to verify possible interference of the frenulum with the resting position of the tongue and lips. Infants whose mothers agreed with surgery were referred for lingual frenotomy, which was performed by an otolaryngologist.

Topical anesthetic was used for the procedure. Using a grooved director, the tongue was raised for exposure of the lingual frenulum. Sterile curved Metzenbaum scissors were used for the incision. The scissors were directed perpendicular to the lingual frenulum and slid across the central surface of the grooved director to the angle of the tongue with the floor of the mouth, preserving muscle tissue and sublingual caruncles. Subsequently, the instruments were removed from the oral cavity, and the surgeon's index finger was used to remove the possible remaining frenulum tissues and to assist hemostasis. Suture was not necessary. Immediately after the surgical procedure, the infants were breastfed to perform tongue movements, as well as to detect possible difficulties during breastfeeding.

Thirty days after the surgical procedure, the infants returned for reassessment of the resting position of the tongue and lips. Infants with ankyloglossia that did not undergo surgery were also reassessed at the same period.

All reassessments were conducted by the main researcher (trained and calibrated) of this study and videorecorded for later review by a trained and calibrated second examiner. All reassessments performed by the second examiner were blind to ensure the methodological rigor of the research. After a blind analysis of the second researcher, the data were tabulated in an MS-Excel (Microsoft Corp., Redmond, WA, USA) spreadsheet, using the IBM SPSS Statistics for Windows version 25.0 (IBM Corp., Armonk, NY, USA) software for statistical treatment. The McNemar test was applied to verify possible differences in the position of the lips and the tongue at rest between the two observation moments, that is, in the initial and final assessments for infants who did not undergo surgery (CG), for those who underwent lingual frenotomy (EG), and for the entire sample. To compare possible differences in the position of the lips and the tongue at rest between the two groups (EG and CG), the likelihood-ratio test was applied at each moment of the evaluation (initial and final). A significance level of $5 \%$ was adopted for all statistical tests.

\section{Results}

A total of 448 infants were diagnosed with ankyloglossia; however, 114 (25.45\%) were excluded from the study due to the impossibility of clinical assessment of the tongue and lip position at rest, since they were awake.

Of the 334 infants included in the present study, 130 (38.92\%) were females and 204 (61.08\%) were males. Out of the total sample, 243 (72.75\%) underwent lingual frenotomy, being 101 (41.56\%) females and $142(58.44 \%)$ males. Of the 91 infants (27.25\%) who did not undergo the surgical procedure, 29 (31.87\%) were females and $62(68.13 \%)$ were males.

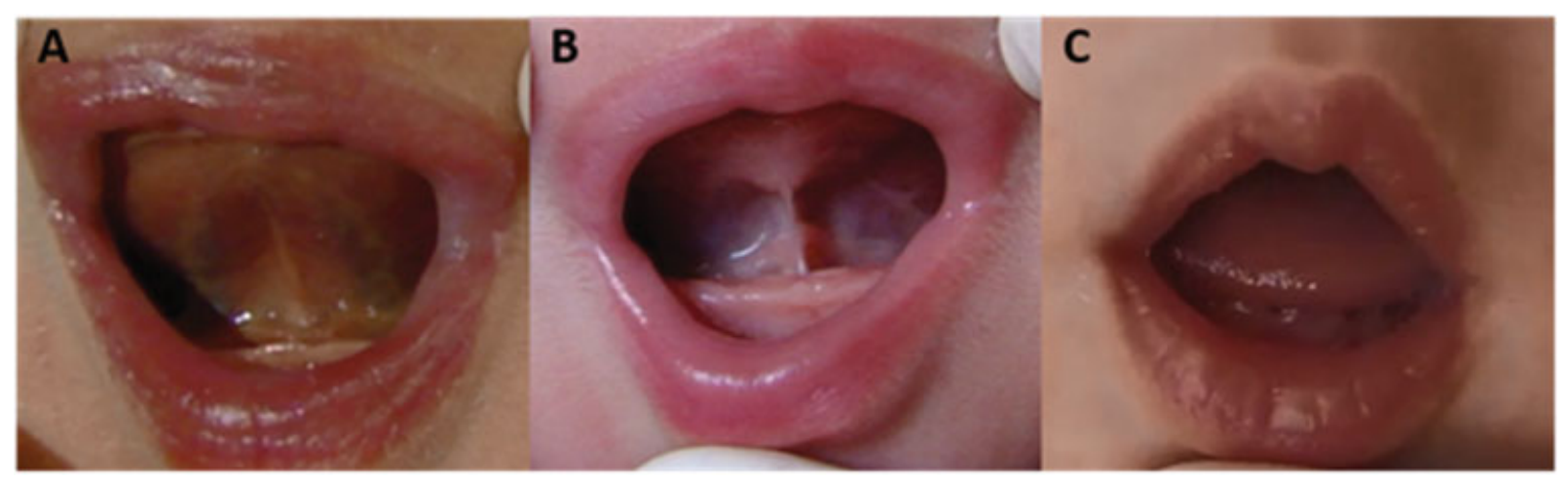

Fig. 3 Tongue position at rest. In A, elevated, in B, elevated, but being pulled down by the lingual frenulum, and in C, down-positioned in the oral cavity. 
72 Effect of Lingual Frenotomy on Tongue and Lip Rest Position Martinelli et al.

Table 1 Position of the lips at rest at the initial and final assessments of both groups of infants with ankyloglossia: the group who underwent lingual frenotomy and the group who did not undergo surgery

\begin{tabular}{|c|c|c|c|c|c|c|}
\hline \multirow[t]{2}{*}{ Surgery } & \multirow[t]{2}{*}{ Lip position at initial assessment } & \multicolumn{3}{|c|}{ Lip position at final assessment } & \multirow[t]{2}{*}{ Total } & \multirow[t]{2}{*}{ p-value } \\
\hline & & open & half-hopen & closed & & \\
\hline \multirow[t]{8}{*}{ No (CG) } & \multirow[t]{2}{*}{ open } & 11 & 1 & 0 & 12 & \multirow[t]{8}{*}{0.580} \\
\hline & & $12.10 \%$ & $1.10 \%$ & $0.00 \%$ & $13.20 \%$ & \\
\hline & \multirow[t]{2}{*}{ half-open } & 3 & 45 & 5 & 53 & \\
\hline & & $3.30 \%$ & $49.50 \%$ & $5.50 \%$ & $58.20 \%$ & \\
\hline & \multirow[t]{2}{*}{ closed } & 0 & 6 & 20 & 26 & \\
\hline & & $0.00 \%$ & $6.60 \%$ & $22.00 \%$ & $28.60 \%$ & \\
\hline & \multirow[t]{2}{*}{ Total } & 14 & 52 & 25 & 91 & \\
\hline & & $15.40 \%$ & $57.10 \%$ & $27.50 \%$ & $100.00 \%$ & \\
\hline \multirow[t]{8}{*}{ Yes (EG) } & \multirow[t]{2}{*}{ open } & 0 & 0 & 14 & 14 & \multirow[t]{8}{*}{$<0.001^{*}$} \\
\hline & & $0.00 \%$ & $0.00 \%$ & $5.80 \%$ & $5.80 \%$ & \\
\hline & \multirow[t]{2}{*}{ half-open } & 0 & 0 & 126 & 126 & \\
\hline & & $0.00 \%$ & $0.00 \%$ & $51.90 \%$ & $51.90 \%$ & \\
\hline & \multirow[t]{2}{*}{ closed } & 0 & 0 & 103 & 103 & \\
\hline & & $0.00 \%$ & $0.00 \%$ & $42.40 \%$ & $42.40 \%$ & \\
\hline & \multirow[t]{2}{*}{ Total } & 0 & 0 & 243 & 243 & \\
\hline & & $0.00 \%$ & $0.00 \%$ & $100.00 \%$ & $100.00 \%$ & \\
\hline
\end{tabular}

Abbreviations: CG, control group; EG, experimental group.

McNemar test.

*Statistical Significance.

Table 2 Resting position of the tongue at the initial and final assessments of both groups of infants with ankyloglossia: the group who underwent lingual frenotomy and the group who did not undergo surgery

\begin{tabular}{|c|c|c|c|c|c|c|}
\hline \multirow[t]{2}{*}{ Surgery } & \multirow{2}{*}{$\begin{array}{l}\text { Tongue position at } \\
\text { initial assessment }\end{array}$} & \multicolumn{3}{|c|}{ Tongue position at final assessment } & \multirow[t]{2}{*}{ Total } & \multirow[t]{2}{*}{ p-value } \\
\hline & & down-positioned & elevated & elevated pulled down & & \\
\hline \multirow[t]{8}{*}{ No (CG) } & \multirow[t]{2}{*}{ down-positioned } & 87 & 0 & 0 & 87 & \multirow[t]{8}{*}{0,250} \\
\hline & & $95.60 \%$ & $0.00 \%$ & $0.00 \%$ & $95.60 \%$ & \\
\hline & \multirow[t]{2}{*}{ elevated } & 0 & 0 & 0 & 0 & \\
\hline & & $0.00 \%$ & $0.00 \%$ & $0.00 \%$ & $0.00 \%$ & \\
\hline & \multirow[t]{2}{*}{ elevated pulled down } & 3 & 0 & 1 & 4 & \\
\hline & & $3.30 \%$ & $0.00 \%$ & $1.10 \%$ & $4.40 \%$ & \\
\hline & \multirow[t]{2}{*}{ Total } & 90 & 0 & 1 & 91 & \\
\hline & & $98.90 \%$ & $0.00 \%$ & $1.10 \%$ & $100.00 \%$ & \\
\hline \multirow[t]{8}{*}{ Yes (EG) } & \multirow[t]{2}{*}{ down-positioned } & 3 & 211 & 0 & 214 & \multirow[t]{8}{*}{$<0.001^{*}$} \\
\hline & & $1.20 \%$ & $86.80 \%$ & $0.00 \%$ & $88.10 \%$ & \\
\hline & \multirow[t]{2}{*}{ elevated } & 0 & 0 & 0 & 0 & \\
\hline & & $0.00 \%$ & $0.00 \%$ & $0.00 \%$ & $0.00 \%$ & \\
\hline & \multirow[t]{2}{*}{ elevated pulled down } & 0 & 29 & 0 & 29 & \\
\hline & & $0.00 \%$ & $11.90 \%$ & $0.00 \%$ & $11.90 \%$ & \\
\hline & \multirow[t]{2}{*}{ Total } & 3 & 240 & 0 & 243 & \\
\hline & & $1.20 \%$ & $98.80 \%$ & $0.00 \%$ & $100.00 \%$ & \\
\hline
\end{tabular}

Abbreviations: CG, control group; EG, experimental group.

McNemar test.

*Statistical Significance. 
Table 3 Comparison of tongue and lip position at rest at the initial and final assessments of both groups of infants with ankyloglossia: the group who underwent lingual frenotomy and the group who did not undergo surgery

\begin{tabular}{|c|c|c|c|c|c|c|}
\hline \multirow[t]{3}{*}{ Variable } & \multirow[t]{3}{*}{ Category } & \multicolumn{4}{|c|}{ Surgery } & \multirow[t]{3}{*}{ p-value } \\
\hline & & \multicolumn{2}{|c|}{ No (CG) } & \multicolumn{2}{|c|}{ Yes (EG) } & \\
\hline & & Freq. & Perc. & Freq. & Perc. & \\
\hline \multirow{3}{*}{$\begin{array}{l}\text { Lip position at } \\
\text { initial assessment }\end{array}$} & open & 12 & $13.20 \%$ & 14 & $5.80 \%$ & \multirow[t]{3}{*}{$0.015^{*}$} \\
\hline & half-open & 53 & $58.20 \%$ & 126 & $51.90 \%$ & \\
\hline & closed & 26 & $28.60 \%$ & 103 & $42.40 \%$ & \\
\hline \multirow[t]{2}{*}{ Tongue position at initial assessment } & down-positioned & 87 & $95.60 \%$ & 214 & $88.10 \%$ & \multirow[t]{2}{*}{$0.040^{*}$} \\
\hline & elevated pulled down & 4 & $4.40 \%$ & 29 & $11.90 \%$ & \\
\hline \multirow[t]{3}{*}{ Lip position at final assessmentl } & open & 14 & $15.40 \%$ & 0 & $0.00 \%$ & \multirow[t]{3}{*}{$<0.001^{*}$} \\
\hline & half-open & 52 & $57.10 \%$ & 0 & $0.00 \%$ & \\
\hline & closed & 25 & $27.50 \%$ & 243 & $100.00 \%$ & \\
\hline \multirow[t]{3}{*}{ Tongue position at final assessment } & down-positioned & 90 & $98.90 \%$ & 3 & $1.20 \%$ & \multirow[t]{3}{*}{$<0.001^{*}$} \\
\hline & elevated & 0 & $0.00 \%$ & 240 & $98.80 \%$ & \\
\hline & elevated pulled down & 1 & $1.10 \%$ & 0 & $0.00 \%$ & \\
\hline
\end{tabular}

Abbreviations: CG, control group; EG, experimental group; Freq., frequency; Perc., percentage.

Likelihood-ratio test.

*Statistical Significance.

- Tables 1 and 2 show, respectively, that there was a statistically significant difference $(p<0.001)$ in the position of the tongue and lips at rest in infants with ankyloglossia before and after the surgical procedure, demonstrating that lingual frenotomy improves lip closure and coupling of the tongue at rest against the hard palate.

When comparing the position of the tongue and lips at rest at the initial and final assessments, the statistical analysis demonstrated statistically significant differences between both groups of infants with ankyloglossia: the group who underwent lingual frenotomy and those who did not undergo surgery, as shown in - Table 3.

\section{Discussion}

The present study was conducted to verify the effect of lingual frenotomy on the resting position of the tongue and lips in infants with ankyloglossia. For this, the Neonatal Tongue Screening Test was administered for the assessment and diagnosis of ankyloglossia. ${ }^{28}$ The administration of Neonatal Screening Tests is essential, since they allow the diagnosis of alterations, as well as early interventions, which reduce and/or eliminate factors that may hinder the proper development of the baby. ${ }^{30}$

In the present study, of the 334 infants diagnosed with ankyloglossia, the majority (61.08\%) was male, a finding that is in agreement with the literature. ${ }^{31-33}$

The results from the final assessments (- Tables 1 and 2 ) demonstrated that the infants with ankyloglossia who did not undergo lingual frenotomy maintained the lip and tongue positions as observed in the initial assessment $(p>0.05)$, in contrast to those who underwent surgery $(p<0.001)$, confirming the results from the studies conducted by Martinelli et al. ${ }^{14,34}$ The literature states that until the age of
6 months old, there is no dissociation of tongue, lips and jaw movements ${ }^{35-37}$; thus, we can infer that in cases of ankyloglossia, when the tongue remains down-positioned at rest due to the restriction caused by the lingual frenulum, there are also interferences with the jaw (lowering) and the lips (opening). These findings justify the importance of early diagnosis and treatment of ankyloglossia, not only due to breastfeeding difficulties, as recommended by some governmental guidelines, ${ }^{38,39}$ but also to prevent the down tongue position, which interferes with orofacial growth.

- Table 3 demonstrates that there was a statistically significant difference $(p<0.001)$ in the position of the lips and tongue at rest between both groups of infants: those who underwent lingual frenotomy and those who did not undergo surgery. These results demonstrated that lingual frenotomy enables coupling of the tongue at rest against the hard palate and improves lip closure. Cockley et al. reported that, although the influence of tongue position on maxillary arch development is well documented, it rarely gets due attention in the clinical setting. ${ }^{1}$

As the understanding of the effects of ankyloglossia increases, it will be possible to use this knowledge to treat it properly, allowing both the healthy development of structures and performance of orofacial functions. ${ }^{1}$ Thus, the present study shows that ankyloglossia interferes with the correct position of both the tongue and the lips at rest, being one more reason to justify the early release of the lingual frenulum.

The results from the present study contribute to the indication of lingual frenotomy, which has been performed when both difficulties in breastfeeding and in tongue coupling against the palate are detected.

As a possible limitation of the present work, we highlight the impossibility of randomization and double-blindness of the sample for ethical reasons. 
Future research comparing the hard palate width of infants with and without ankyloglossia may complement the findings of the present research.

\section{Conclusion}

In the present study, lingual frenotomy enabled infants diagnosed with ankyloglossia to maintain both tongue coupling against the hard palate and closed lips at rest.

\section{References}

1 Cockley L, Lehman A. The Ortho missing link: could it be tied to the tongue. JAOS 2015;15(01):18-21

2 Genovez TGP, Mendonça JSC, Galante JMB, Almeida ALPF, Gomide MR, Dalben G. Hypodevelopment of the tongue: embryonic basis and consequences for the development of craniofacial structures. Int J Dent Health Sci 2016;3(04):1183-1188

3 Salles F, Anchieta M, Costa Bezerra P, Torres ML, Queiroz E, Faber J. Complete and isolated congenital aglossia: case report and treatment of sequelae using rapid prototyping models. Oral Surg Oral Med Oral Pathol Oral Radiol Endod 2008;105(03):e41-e47

4 Nayyer M, Saleem T, Ahmed B, Azad AA, Aslam A, Ovais N. Aglossia: a rare case report and review. Pak Oral Dent J 2015; 35(04):762-766

5 Bommarito S, Zanato LE, Vieira MM, Angelieri F. Aglossia: Case Report. Int Arch Otorhinolaryngol 2016;20(01):87-92

6 Jang SJ, Cha BK, Ngan P, Choi DS, Lee SK, Jang I. Relationship between the lingual frenulum and craniofacial morphology in adults. Am J Orthod Dentofacial Orthop 2011;139)4, Suppl): e361-e367

7 Srinivasan B, Chitharanjan AB. Skeletal and dental characteristics in subjects with ankyloglossia. Prog Orthod 2013;14:44

8 Defabianis P. Ankyloglossia and its influence on maxillary and mandibular development. (A seven year follow-up case report). Funct Orthod 2000;17(04):25-33

9 Meenakshi S, Jagannathan N. Assessment of lingual frenulum lengths in skeletal malocclusion. J Clin Diagn Res 2014;8(03): 202-204

10 Pompéia LE, Ilinsky RS, Ortolani CLF, Faltin Júnior K. A influência da anquiloglossia no crescimento e desenvolvimento do sistema estomatognático. Rev Paul Pediatr 2017;35(02):216-221

11 Huang Y, Quo S, Berkowski JA, Guilleminault C. Short Lingual Frenulum an Obstructive Sleep Apnea in Children. Int J Pediatr Res 2015;1:1

12 Yoon AJ, Zaghi S, Ha S, Law CS, Guilleminault C, Liu SY. Ankyloglossia as a risk factor for maxillary hypoplasia and soft palate elongation: A functional - morphological study. Orthod Craniofac Res 2017;20(04):237-244

13 Guilleminault C, Huseni S, Lo L. A frequent phenotype for paediatric sleep apnoea: short lingual frenulum. ERJ Open Res 2016;2 (03):00043-02016

14 Martinelli RLC, Marchesan IQ, Berretin-Felix G. Rest position of the tongue in infants with and without lingual frenulum alteration. Int J Orofacial Myology 2016;42:43-48

15 Berry J, Griffiths M, Westcott C. A double-blind, randomized, controlled trial of tongue-tie division and its immediate effect on breastfeeding. Breast Med 2011;0:1-5

16 Buryk M, Bloom D, Shope T. Efficacy of neonatal release of ankyloglossia: a randomized trial. Pediatrics 2011;128(02): 280-288

17 Hogan M, Westcott C, Griffiths M. Randomized, controlled trial of division of tongue-tie in infants with feeding problems. J Paediatr Child Health 2005;41(5-6):246-250
18 Emond A, Ingram J, Johnson D, et al. Randomised controlled trial of early frenotomy in breastfed infants with mild-moderate tongue-tie. Arch Dis Child Fetal Neonatal Ed 2014;99(03):F189-F195

19 Dollberg S, Botzer E, Grunis E, Mimouni FB. Immediate nipple pain relief after frenotomy in breast-fed infants with ankyloglossia: a randomized, prospective study. J Pediatr Surg 2006;41(09): $1598-1600$

20 Martinelli RL, Marchesan IQ, Gusmão RJ, Honório HM, BerretinFelix G. The effects of frenotomy on breastfeeding. J Appl Oral Sci 2015;23(02):153-157

21 Silva MC, Costa MLVCM, Nemr NK, Marchesan IQ. Frênulo de língua alterado e interferência na mastigação. Rev CEFAC 2009;11 (Suppl 3):363-369

22 Queiroz Marchesan I. Lingual frenulum: classification and speech interference. Int J Orofacial Myology 2004;30:31-38

23 Ostapiuk B. Asymmetry in sound production in persons with ankyloglossia. Logopedia 2010;39/40:113-137

24 Hanson M, Mason R. OrofacialMyology: International Perspectives (Vol. 2nd). Springfield, IL: Charles C Thomas Publisher; 2003

25 Graber T, Vanarsdall R Jr, Vig K, Damon D. Treatment of the Face with Biocompatible Orthodontics. In: Orthodontics: Current Principles and Techniques (Vol. 4th). St. Louis, MI: Elsevier Mosby; 2005:753-779

26 Proffit WR. Equilibrium theory revisited: factors influencing position of the teeth. Angle Orthod 1978;48(03):175-186

27 Martinelli RLC, Marchesan IQ, Gusmão RJ, Rodrigues AC, BerretinFelix G. Histological characteristics of altered human lingual frenulum. Int J Pediatr Child Health 2014;2:5-9

28 Martinelli RLC, Marchesan IQ, Lauris JR, Honório HM, Gusmão RJ Berretin-felix G. Validity and reliability of the neonatal tongue screening test. Rev CEFAC 2016;18(06):1323-1331

29 Khan RL, Raya JP, Nunes LM. Avaliação do Estado Comportamental durante o Sono em Recém-Nascidos. J Epilepsy Clin Neurophysiol 2009;15(01):25-29

30 Medeiros HEGB, Leite CRM, Santos JF, Ribeiro Neto PF, Martinelli RLC, Cavalcanti RVA. Sistema de apoio à decisão na realização e acompanhamento do teste da linguinha. RBCA 2016;8(01):104-113

31 Khoo AK, Dabbas N, Sudhakaran N, Ade-Ajayi N, Patel S. Nipple pain at presentation predicts success of tongue-tie division for breastfeeding problems. Eur J Pediatr Surg 2009;19(06):370-373

32 Messner AH, Lalakea ML, Aby J, Macmahon J, Bair E. Ankyloglossia: incidence and associated feeding difficulties. Arch Otolaryngol Head Neck Surg 2000;126(01):36-39

33 Martinelli RLC, Marchesan IQ, Lauris JR, Honório HM, Gusmão RJ, Berretin-Felix G. Validation of the Lingual Frenulum Protocol for infants. Int J Orofacial Myology 2016;42:5-13

34 Martinelli RLC, Marchesan IQ Honório HM, Berretin-Felix GPostura de lábios no repouso em bebês com e sem alteração do frênulo lingual Anais do $10^{\circ}$ Encontro Brasileiro de Motricidade Orofacial. 2017Belo Horizonte, MG. São Paulo: Associação Brasileira de Motricidade Orofacial; 2017.

35 Morris SE, Klein MD. Pre-Feeding Skills (Second ed.): Therapy Skill Builders. 2000

36 Morris SE. Pre-Speech Assessment Scale. Clifton: J.A. Preston Corporation; 1982

37 Morris SE. A Profile of the Development of Oral-Motor Skills in Early Infancy-Birth to 12 Months [Manual]. Faber, VA1991

38 The American Academy of Pediatric Dentistry Guideline on Pediatric Oral Surgery. Reference manual. [periódicos na Internet]. 2015; 40(6):372-82. [cited 2019 oct 03] Available from: http://www. aapd.org/media/Policies_Guidelines/G_OralSurgery.pdf

39 Rowan-Legg A. Canadian Pediatric Society Ankyloglossia and breastfeeding, Position Statement, 2015. [cited 2019 oct 03] Available from: http://www.cps.ca/documents/position/ankyloglossia-breastfeeding 